\title{
Policies for Green Computing and E-Waste in Nigeria
}

\author{
Shedrack Mmeah \\ Department of Computer \\ Science, Ken Saro Wiwa \\ Polytechnic, Bori, \\ Rivers State - Nigeria
}

\author{
Barida Baah \\ Department of Computer \\ Science, Ebonyi State \\ University, Abakaliki - \\ Nigeria
}

\author{
Abasiama G. Akpan \\ Department of Computer \\ Science, Ebonyi State \\ University, Abakaliki - \\ Nigeria
}

\begin{abstract}
Computers today are an integral part of individuals' lives all around the world, but unfortunately these devices are toxic to the environment given the materials used, their limited battery life and technological obsolescence. Individuals are concerned about the hazardous materials ever present in computers, even if the importance of various attributes differs, and that a more environment friendly attitude can be obtained through exposure to educational materials. In this paper, we aim to delineate the problem of e-waste in Nigeria and highlight a series of measures and the advantage they herald for our country and propose a series of action steps to develop in these areas further. It is possible for Nigeria to have an immediate economic stimulus and job creation while moving quickly to abide by the requirements of climate change legislation and energy efficiency directives. The costs of implementing energy efficiency and renewable energy measures are minimal as they are not cash expenditures but rather investments paid back by future, continuous energy savings.
\end{abstract}

Keywords: Green Computing, eco trends, climate change, e-waste and eco-friendly

\section{INTRODUCTION}

Green computing is the environmentally responsible and ecofriendly use of computers and their resources. In broader terms, it is also defined as the study of designing, manufacturing/engineering, using and disposing of computing devices in a way that reduces their environmental impact. Green computing aims to attain economic viability and improve the way computing devices are used. Green IT practices include the development of environmentally sustainable production practices, energy efficient computers and improved disposal and recycling procedures.

To promote green computing concepts at all possible levels, the following four complementary approaches are employed:

- Green use: Minimizing the electricity consumption of computers and their peripheral devices and using them in an eco-friendly manner

- Green disposal: Re-purposing an existing computer or appropriately disposing of, or recycling, unwanted electronic equipment

- Green design: Designing energy-efficient computers, servers, printers, projectors and other digital devices

- Green manufacturing: Minimizing waste during the manufacturing of computers and other subsystems to reduce the environmental impact of these activities

Government regulatory authorities also actively work to promote green computing concepts by introducing several voluntary programs and regulations for their enforcement.[1] At a macro level, as the ecotrends are sweeping across the globe, the European Union, for example, has established guidelines for a computers' end of life (EOL) making manufacturers responsible for the implementation of measures during and after the sale to ensure that their products are sold and then collected, deposited or recycled so as to reduce their impact on the environment.
Europe's strong stance on the environment has strong support from it newest member states in Eastern and Central Europe. These transitioning economies are in the process of transferring legislation and incorporating EU policies. Nigeria has developed a National Strategy for Sustainable Development for 20 13-2020-2030 which set out the following priorities: climate change and clean energy, sustainable consumption and waste management, conservation and management of natural resources. However, there is still a gap between legislation and practice [2]. Particularly, in the reduction of e - waste, Nigeria is working to set up the infrastructure to facilitate these directives that closely mirror those established by the EU. However, as public awareness of environmental standards has increased, companies have grown more compliant with environmental standards and regulations. Currently, Nigeria is situated at the bottom of the list according to its Environmental Performance Index, having less scores for health impacts and forests and needing to improve its management of fisheries and water resources.

In this paper, we aim to delineate the problem of e-waste in Nigeria and highlight a series of measures and the advantage they herald for our country.

\subsection{E-WASTE}

"Electronic waste" may be defined as discarded computers, office electronic equipment, entertainment device electronics, mobile phones, television sets, and refrigerators. This includes used electronics which are destined for reuse, resale, salvage, recycling, or disposal. Others are re-usable (working and repairable electronics) and secondary scrap (copper, steel, plastic, etc.) to be "commodities", and reserve the term "waste" for residue or material which is dumped by the buyer rather than recycled, including residue from reuse and recycling operations. Because loads of surplus electronics are frequently commingled (good, recyclable, and non- 
recyclable), several public policy advocates apply the term "ewaste" broadly to all surplus electronics. [3]

Today the electronic waste recycling business is in all areas of the developed world a large and rapidly consolidating business. People tend to forget that properly disposing or reusing electronics can help prevent health problems, create jobs, and reduce greenhouse-gas emissions. Part of this evolution has involved greater diversion of electronic waste from energy-intensive down cycling processes (e.g., conventional recycling), where equipment is reverted to a raw material form. This recycling is done by sorting, dismantling, and recovery of valuable materials. This diversion is achieved through reuse and refurbishing. The environmental and social benefits of reuse include diminished demand for new products and virgin raw materials (with their own environmental issues); larger quantities of pure water and electricity for associated manufacturing; less packaging per unit; availability of technology to wider swaths of society due to greater affordability of products; and diminished use of landfills.

If one attempted to break the e-waste recycling process into several connected steps, the following cycle would be of use:

1) Collection

2) Sorting/dismantling and pre-processing (i.e. sorting, dismantling, mechanical treatment)

3) End-processing (i.e. refining and disposal) — see Table 1

Table 1: Recycling chain for e-waste

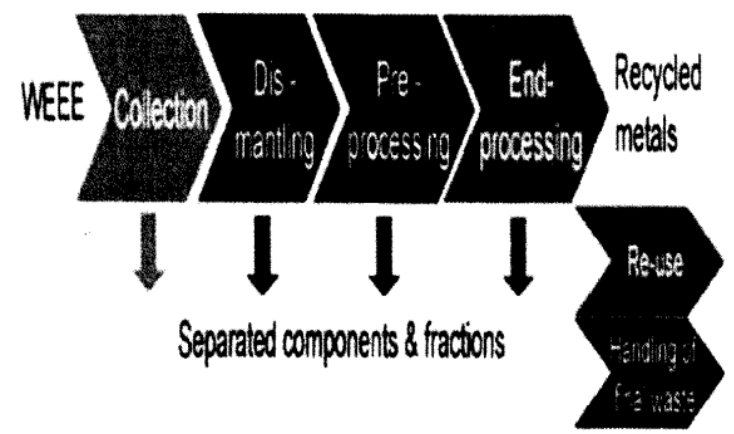

Taken from UNEP 2009, Recycling -from E-waste to resources

On the whole, the efficiency of the entire recycling chain is inextricably linked to the efficiency of each step and to how well the interfaces between these interdependent steps are managed.

Therefore, in a context characterized by fundamental changes in demographic and pronounced regional disparities, sharp dynamics of technical progress combined with a relative increase in living standards significantly contribute to increased sales of electronic products and consumer goods which translate, at the end their lifetime, in an increase in the amount of e-waste generated in Nigeria. Of course, a potential e-waste management system must be carefully tailored and well organized, so it would be able to collect, recycle and dispose of electronic used equipment. E-waste collection from households in Nigeria is organized through three collection channels: by organizing a collection day at fixed dates from the population, by giving back to the store the old equipment when purchasing a new one (free take- back system) or by giving it directly to the municipal collection centers. [4] Regarding the acquisition trends of c-waste collection, national studies conducted in 2008 and 2009 on the electronic market revealed the following:

- $\quad$ penetration of small appliances increased;

- there is a tendency to abandon the use of old equipment which are more than five years;

- $\quad$ although the percentage of people who keep in their household non-operational equipment decreased, many of them still keep it because they don't know very well the alternatives. They should be attracted by offering discounts on the purchase of new equipment, or by collecting the old ones from their home.

Consequently, one can say that in Nigeria, the difference between the amount of equipment placed on the market and the amount of equipment collected from consumers is the quite high compared with other countries in the AU.

There are special legal provisions for c-waste and used batteries, but their implementation and enforcement have a long way to go. Good practices are visible though there is a monthly national campaign for collecting e-waste, encouraging people to put old fridges, TV sets, washing machines and computers outside their houses, which the local waste management company then collects. Due to this campaign, the average amount collected in 2009 was almost $2 \%$ of the national target, experts estimated. E-waste associations had an online media campaign in 2009 to advertise their services. In May-June 2010 a public awareness campaign, funded by e-waste management companies, called for photos and videos of e-waste, which it called "the monsters of your community".[3]

The media campaign is backed by the Ministry of Environment - a good example of cooperation between civil society, business organisations and the government. Perhaps as a result, research on e-waste-related attitudes and behaviours, conducted in Nigeria urban areas, has shown positive trends in terms of a willingness to recycle dysfunctional appliances. At the same time, however, $70 \%$ of the Nigeria urban population surveyed is not aware of the laws and regulations related to c-waste.

The attitudes and habits concerning electrical and electronic waste can be discerned from the following data, issued by a recent survey done by ECOTIC (data for the survey was collected between August 10 and August 31 2014, on a sample of 1,000 people from the urban area, aged between 15 and 65):

- some $60 \%$ of Nigerians who live in urban areas say they separate waste for recycling, mainly plastic, paper, glass and metallic products; 

waste;

Only $4 \%$ separately collect electrical and electronic

- $\quad 87.5 \%$ of respondents know that they can recycle this kind of waste; -.

- when asked "Why do you think electrical waste should be recycled?", most of Nigerians relate to the re-use of materials - $38 \%$, environmental reasons $-36 \%$ and to repairing and putting back into use$15 \%$.

- only $36 \%$ of respondents have actually turned in electrical waste to licensed entities, such as specially arranged centres in different areas of the city (over $30 \%$ took the electrical waste in such places), in stores when buying a new product (26\%), and specialized firms (13\%).

- $6 \%$ gave such waste to people who periodically pass through residential areas to collect scrap iron.

- the most common waste equipment Romanians recycle are TV sets- $49 \%$ - refrigerators $-33 \%$ and washing machines $-28 \%$.

- of the $64 \%$ of respondents who don't give electrical waste to licensed operators, $27 \%$ say they give it to people who collect scrap iron waste on the streets, $26 \%$ keep them in their homes and $34 \%$ give them to friends or relatives.

- most respondents say they keep electrical waste for parts or because they intend to repair them, that they don't know about any disposal facilities nearby, they don't know what to do with them or that they can be recycled; others say they just lack the time.

- $\quad$ Nigerians should collect $4 \mathrm{~kg}$ of electrical waste per year per person for recycling, according to EU quotas, but the recorded results don't exceed $1.5 \mathrm{~kg}$ per capita.

The factor that would most motivate the Romanians to giveup non-functional home electronics and appliances are buyback campaigns, where consumers receive a discount on the purchase of new equipment when they give in return the old ones. Furthermore, surveys indicate that over $90 \%$ of respondents admit that selective waste collection activity is important, but still they do not operate in this direction. They are willing to adopt an ecological environmental behaviour regarding electronic equipment only to the extent that this does not require great efforts on their part.

There are several implications for these findings. If these implications should be translated into steps of an e-waste programme, they should focus on the following aspects:

- $\quad$ First and foremost, consumers need to be educated regarding the toxicity of computers and the problems of e - waste. The results of the survey suggest that when presented with information the consumers positive attitudes toward green computing and e-waste collection increase significantly in. This education would best be carried out by public policy holders, educational institutions and various non - profit agencies such as the Green Electronics Council on a prolonged basis to initiate attitude change.

- In 2001, the Western Electronic Product Stewardship Initiative (WEPSI) proposed developing environmental assessment criteria of electronics as a means to direct governments and other entities into environmentally better purchasing decisions. The EPEAT system is used in at least eight nations including the US and Canada and is used to identify environmentally friendly electronics; however, expansion of this system is needed in more countries as the proliferation of e waste continues. In this system electronics are evaluated based such criteria as reduction of harmful materials, recyclability, energy conservation, corporate performance, end - of life(EOL) management, and product longevity. EPEAT registered computers have reduced levels of toxic metals, are energy efficient and are easy to upgrade and recycle. Although many manufacturers subscribe to the EPEAT system, getting the message to consumers is not without difficulties. Findings show that consumers are proactive regarding energy savings; however, regarding other components of computers, such as batteries and materials, they lack the knowledge necessary to make informed choices.

- Marketing can play a vital role in increasing favorable attitudes towards green computing and prompting sustainable development of computers and other similar devices minimizing their impact on the environment while satisfying consumers' needs and wants. Depending on the country the role of government in moderating consumer purchasing behavior of green computers and other electronics through educational materials could be perceived both positively and negatively.

Electronics manufacturers must realize that consumers in developing nations are environmentally conscious and desire access to eco - friendly computer products and accessories. Hence, manufacturers that subscribe to EPEAT should develop labeling and symbols that are incorporated into packaging and product design to further communicate their support of green computing initiatives such as EOL. Further, these manufacturers should communicate this distinction as a point of brand differentiation when developing advertising messages. Until now, differentiation among computer manufacturers has been based on after - sale service, brand reputation, speed, and technological capabilities. Additionally, product strategies should include educational seminars provided to resellers in the form of employee trainings so that they are better able to communicate the features and benefits of "green" computer brands and models to consumers in developed, transitioning and LDC countries.

As an overall recommendation, the development of collaboration between institutions with responsibilities in waste management should be enhanced and more support rendered by competent state bodies to private sector is 
required. There are insufficient actions of ecological parties and nongovernmental organisations to promote solutions and measures for waste management. Environmental awareness of citizens should be continued and intensified and the national awareness campaign on the importance of selective collection is still needed to be implemented. [5]

Keeping a close interest in e-waste recycling is important considering the hazardous substances contained in many of the products in this waste stream. One key issue is the multicriteria nature of the challenge: it is desirable to maximize reuse of equipment and economic development while minimizing environmental burdens and economic costs.

\section{CONCLUSIONS}

Currently, c-waste receives more and more public attention as it is considered to be one of the fastest-growing waste streams. This sector operates within a long-established legislative framework that covers issues such as product safety, energy labeling, minimum efficiency requirements, ecodesign and waste. Two Directives (2008/34 and 2008/3 5) on waste electrical and electronic equipment and the restriction of the use of certain hazardous substances in electrical and electronic 'equipment were introduced in 2008 in order to amend the Directive 2002/96/EC and Directive 2002/95/EC. The EU aims to take measures to prevent the generation of electrical and electronic waste and to promote reuse, recycling and other forms of recovery in order to reduce the quantity of such waste by encouraging manufacturers to design products with the environmental impacts in mind throughout their entire life cycle.

In Nigeria, it can be said that environmental issues still evolve on a rocky path, though with visible signs of improvement. In order to develop a green agenda in the country, several steps have been looked at:

- Key stakeholders should be educated in order to promote a green approach to c-waste and a cleantech approach to the environment.

- A set of economic indicators should be publicly available in order to assess the environmental impact of e-waste use, e.g. monitoring the availability of environmental content on the internet as a measure of the success of awareness-raising efforts.

- A set of environmental indicators should be developed in order to assess the impact of c-waste on the environment, and made publicly available.

- Primary research on c-waste collection and the environment should be encouraged through funding. Romanian environmental protection officials should be more actively involved in international discussions taking place at green computing events.

- Civil society organisations should have a more active role in promoting the green computing agenda, along with businesses and governmental agencies.

In conclusion, computers today are an integral part of individuals' lives all around the world; but unfortunately these devices are toxic to the environment given the materials used, their limited battery life and technological obsolescence. Individuals are concerned about the hazardous materials ever present in computers, even if the importance of various attributes differs, and that a more environment - friendly attitude can be obtained through exposure to educational materials. The costs of implementing energy efficiency and renewable energy measures are minimal as they are not cash expenditures but rather investments paid back by future, continuous energy savings. Sustainable innovation, understood as the shift of sustainable technologies, products and services to the market, requires a market creation concept and one common global agenda. The challenge is to raise awareness among all actors of the different sectors in order to realize the innovation potential and to shift to eco-innovations that lead to sustainable consumption and production patterns.

\section{REFERENCES}

[1] Liu, Q., Li, K.Q., Zhao, H., Li, G. and Fa, F.Y. (2009). "The global challenge of electronic waste management", Environmental Science Pollution Research, Vol. 16, pp. 248 - 249.

[2] Seitz, V., Karant, V., Vanti, F., Mihai, O. and Rizkallah, E. (2013). "Attitudes Regarding Green Computing: A Step Towards E - Waste Reduction. “” Western Decision Sciences Institute Annual Meeting, Long Beach, CA, March 18 - 20.

[3] Daedalus, M. 8. (2009). Echipamente electronice si electrice existente in gospodarii si atitudinea populatieifata de echipamentele electron ice uzate, Ecotic. www.ecotic.ro

[4] Ciocoiu N., Burcea S. and Tartlu V. The weee management system in Nigeria: dimension, strengths and weaknesses. Retrived from http://www.um.ase.ro/no 15/1 .pdf.

[5] Vetter, T. (2009). Measuring the impact of Internet governance on sustainable development, report presented in Workshop \#304 at the 4th Internet Governance Forum, Sharm el Sheikh, Egypt, 15-18 November. 